'Klinika za anesteziologiju i reanimaciju, Institut za kardiovaskularne bolesti "Dedinje"

2Služba za trasfuziologiju, Institut za kardiovaskularne bolesti "Dedinje"

${ }^{3}$ Klinika za Vaskularnu hirurgiju, Institut za kardiovaskularne bolesti "Dedinje"

${ }^{4}$ Medicinski Fakultet, Univerzitet u Beogradu

\title{
PERIOPERATIVNA DISEMINOVANA
}

\section{INTRAVASKULARNA KOAGULACIJA}

\section{NAKON HIRURŠKOG LEČENJA}

\section{ANEURIZMATSKE BOLESTI TRBUŠNE AORTE}

\section{- PRIKAZ BOLESNIKA}

\section{PERIOPERATIVE DISSEMINATED}

\section{INTRAVASCULAR COAGULATION}

\section{FOLLOWING THE SURGERY OF}

\section{ABDOMINAL AORTA ANEURYSMAL DISEASE}

Ljiljana Ranković-Ničićl, Evgenija Strugarević2 , Slobodan Tanasković3, Branko Čalija ${ }^{2}$,

Danica Bajčetić, Srđan Babić, Vuk Sotirović3, Predrag Matić3,4, Predrag Gajin ${ }^{3,4}$,

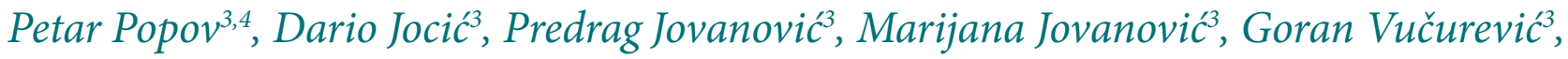
Nenad Ilijevski, ${ }^{3,4}$ Dragoslav Nenezici, ${ }^{3,4}$, Miodrag Jovićl, Đorđe Radak ${ }^{3,4}$

\section{Sažetak}

Diseminovana intravskularna koagulacija (DIK) predstavlja trombohemoragični poremećaj koji se javlja kao sekundarna komplikacija mnogih bolesti. Bolesti krvnih sudova, između ostalih i aneurizmatska bolest aorte, takođe mogu lokalno prouzrokovati aktivaciju koagulacije. Prikazujemo slučaj DIK-a kod pacijentkinje nakon operativnog lečenje aneurizmatske bolesti trbušne aorte.

Bolesnica stara 64 godine primljena je na Kliniku za vaskularnu hirurgiju radi dijagnostike i operativnog lečenja aneurizmatske bolesti trbušne aorte. Multidetektor kompjuterizovana tomografija (MDCT) angiografija verifikovala je aneurizmu abdominalne aorte promera $5.2 \mathrm{~cm}$ uz značajnu aortoilijačnu stenozu te je indikovana resekcija aneurizme uz aortobifemoralnu rekonstrukciju. Sam tok operacije protekao je uredno, ali je po završenoj rekonstrukciji i skidanju klema verifikovana tromboza oba kraka grafta. Hitno je učinjena trombektomija oba kraka i krv poslata na analizu koja je pokazala postojanje DIK-a. Redovno praćenje hemostaznih parametara (faktora koagulacije, funkcije trombocita i rotacione tromboelastometrije (ROTEM-a)) omogućilo je pravovremeno ordiniranje substitucione i antikoagulantne terapije tokom i nakon operativnog zahvata. Devetog postoperativnog dana bolesnica je opuštena u dobrom opštem stanju. Četrdeset dana nakon operacije bolesnica se oseća dobro uz očuvanu vaskularizaciju donjih ekstremiteta. 
Rano prepoznavanje poremećaja koagulacije, tokom operativnog zahvata od strane ordinirajućeg vaskularnog hirurga, u saradanji sa nadležnom službom za transfuziologiju, je od velikog značaja u pravovremenoj detekciji i lečenju DIK-a te sprečavanju teških i potencijalno letalnih hemoragijskih i trombogenih komplikacija kod ovih pacijenata.

Ključne reči: Diseminovana intravskularna koagulacija, aneurizma abdominalne aorte, tromboza.

\section{Summary}

Disseminated intravascular coagulation (DIC) represents a pathological activation of coagulation (blood clotting) mechanisms that happens in response to a variety of diseases. Diseases of the blood vessels, such as aorta aneurysmal disease, could also cause local activation of coagulation. We report a case of DIC in a patient after the surgery of abdominal aorta aneurysm.

64-year-old woman was admitted to the Clinic for vascular surgery for the diagnosis and surgical treatment of abdominal aorta aneurysm. Multidetector computed tomography (MDCT) angiography verified abdominal aorta aneurysm $5.2 \mathrm{~cm}$ in diameter with significant aortoiliac stenosis and thereby aneurysm resection with aortobifemoral reconstruction was indicated. The operation went uneventfully but after completed reconstruction and declamping thrombosis of both limbs of $Y$ graft was verified. Immediate bilateral thrombectomy was performed with the blood being sent for detailed analysis that revealed the presence of DIC. Regular monitoring of hemostatic parameters (coagulation factors, platelet function and rotational thromboelastometry (ROTEM)) enabled timely substitution and administration of anticoagulant therapy during and after surgery. On the 9th postoperative day the patient was discharged in good general condition. Forty days after surgery, the patient feels good with lower limbs vascularization well preserved.

Early recognition of disseminated intravascular coagulation during the surgery by attending vascular surgeon, in cooperation with transfusiology center, is of great importance for well-timed detection and treatment of DIC and preventing serious and potentially lethal hemorrhagic and thrombotic complications in these patients.

Key words: Disseminated intravascular coagulation, abdominal aorta aneurysm, thrombosis.

\section{Uvod}

Diseminovana intravskularna koagulacija (DIK) predstavlja trombohemoragični poremećaj aktivacije koagulacionog sistema koje dovodi do pojave tromboze i krvarenja. [1-3] Javlja kao sekundarna komplikacija mnogih bolesti kao što su zarazne bolesti, obstetričke komplikacije, intravaskularna hemolize, zloćudne bolesti, autoimune i hematološke bolesti, postoperativna stanja i drugo.
[1-3] Karakteriše se pojavom tromboze i krvarenja jer aktivacija koagulacionog procesa sa jedne strane dovodi do pojave mikrotromboze u mikrocirkulaciji, a sa druge kao posledica trombolitičke dijateze i potrošnje trombocita, fibrina i drugih faktora koagulacije dolazi i do aktivacije fibrinolitičkog procesa i pojave krvarenja. DIK nikada nije primarno oboljenje, već se javlja u različitim kliničkim sta- njima. Dva glavna mehanizma koja ga započinju su: oslobađanje tkivnog faktora u cirkulaciju i rasprostranjena oštećenja endotelnih ćeilja. U opsežnim hirurškim intervencijama glavni mehanizam koji pokreće DIK je autoinfuzija tkivnog faktora.[1,2] Želimo da prikažemo slučaj DIK-a tokom operativnog lečenja aneurizmatske bolesti abdominalne aorte.

\section{Prikaz bolesnika}

Bolesnica stara 64 godine, primljena je na Kliniku za vaskuarnu hirurgiju radi dijagnostike i operativnog lečenja aneurizme abdominalne aorte. Na ultrazvučnom pregledu dijametar aneurizme iznosio je oko $5 \mathrm{~cm}$. Negirala je bolove u trbuhu i klaudikacione tegobe. Od udruženih oboljenja i faktora rizika navodi hroničnu obstruktivnu bolest pluća, hipertenziju, hiperlipidemiju, pušenje i faktor nasleđa.

Laboratorijske analize na prijemu bile su u okviru referentnih vrednosti (leukociti $8,4 \times 10^{9} / \mathrm{L}$, eritrociti $3,34 \times 10^{12} / \mathrm{L}$, hemoglobin $132 \mathrm{~g} / \mathrm{L}$, hematokrit 0,39 L/l, trombociti $191 \times 10^{9} / L$, INR (international normalized ratio) - 1,03.) Multidetektor komjuterizovana tomografija angiografijom (MDCT) verifikovana je aneurizma abdominalne aorte, promera $5.2 \mathrm{~cm}$ sa prizidnim trombotičnim masama uz obostrano značajnu aortoilijakalnu stenozu te je indikovana resekcija aneurizme uz aortobifemoralnu rekonstrukciju.

Tokom operacije, na uobičajen način ispreparisani su aorta i femoralne arterije, te pre klemovanja ordinira- na odgovarajuća doza intravenskog frakcionisanog heparina. Nakon završene rekonstrukcije i skidanja klema, verifikuje se tromboza oba kraka " $Y$ " proteze te je učinjena trombektomija istih. Kako nije otkriven tehnički razlog za nastanak tromboze, krv je poslata na kompletnu analizu faktora koagulacije, rotacione tromboelastometrije i funkcije trombocita. Analize su pokazale da je aktivirano vreme koagulacije (ACT) 229, ali i deficit antitrombina III - 43.7\%, INR 1.51, povišen D-dimer 4280, niske vrednosti fibrinogena $1.73 \mathrm{~g} / \mathrm{L}$, a testovi koa- 
gulacije i ROTEM testa ukazali su na pojavu propratne koagulopatije sa značajnim padom broja trombocita u krvnoj slici $\left(77 \times 10^{9} / \mathrm{L}\right)$ i na pojavu akutne diseminovane intravaskularne koagulacije. Ordinirana je terapija heparinom $2500 \mathrm{ij}$, ukupno 18 doza krioprecipitata i 500 jedinica Kybernina (nadoknada antitrombina III) kao i dve doze koncentrovanih eritrocita. Narednog dana ponovljene su sve analize i verifikovana porast antitrombina III na $76.3 \%$, pad D-dimera na 992 , porast fibrinogena na $4.74 \mathrm{~g} / \mathrm{L}$ uz INR 1,14. Rezultati su bili u poboljšanju, ali je i dalje nivo antitrombina bio snižen, u ROTEM testu formiranje koaguluma je bilo smanjeno, uz novu informaciju da je prisutna spontana hiperfibrinoliza manjeg obima. Postignut ugrušak nije bio dovoljne stabilnosti i kvaliteta.

Kontrolni testovi su ponovljeni i narednog dana gde se verifikuje još veći porast fibrinogena $9.68 \mathrm{~g} / \mathrm{L}$, antitrombin III 68.7\%, D-dimer 674. Parametri su ukazali na znake početka inflama- cinog procesa (Fe 3,9; TIBC 28,0; TIBC 31,9; imunoglobulini IgA 0,8; IgG 4,7; IgM 0,3, C3 komplement 0,8). Primenjena je terapija Kyberninom, još 500 i.j., Privigen (humani imunoglobulin) po $10 \mathrm{gr}$ u tri dana i Ferrovin ampule (Gvožđe (III) -hidroksid saharoza) po šemi (dve ampule na drugi dan, sve ukupno 8 ampula). Klinički kod bolesnice prisutni su znaci sistemske inflamacije i arterijske embolizacije u prvom prstu levog stopala.

U postoperativnom toku održava se nizak broj trombocita (60-79×109/L) te je iz terapije isključen niskomolekularni Heparin (Clexan 0,4ml/24h/ sc) a uvedena Arixtra (Fondaparin) $(2,5 \mathrm{mg} / 24 \mathrm{~h} / \mathrm{sc})$ od trećeg postoperativnog dana, a u daljem toku dolazi do oporavka broja trombocita (221×10\%/L). (Tabela 1)

Bolesnica je šestog postoperativnog dana dobila još jednu dozu koncentrovanih eritrocita na vrednosti hemoglobina $81 \mathrm{~g} / \mathrm{L}$. U daljem toku postepeno se stabilizuje hemostazni i imunološki sistem $(\lg A$ 0,8; $\lg G$ 9,0; IgM 0,4; C3 1,3). (Tabela 2 i 3)

Bolesnica je od nultog postoperativnog dana na antibiotskoj terapiji Cefuroksim-om (1.5 gr/12h/i.v.) kojoj se nakon dva dana dodaje i Amikacin (1.5gr/24h/i.v.). Kliničko stanje bolesnice se subjektivno i objektivno znatno popravlja, ishemijske promene prvog prsta levog stopala su u značajnom poboljšanju. Dopler indeksi donjih ekstremiteta opisuju uredan nalaz (arterija tibialis anetrior i posterior (ATP i ADP) obostrano 1,0). Bolesnica je otpuštena devetog postoperativnog dana u dobrom opštem stanju uz predlog terapije Cardiopirinom $100 \mathrm{mg}$ na drugi dan.

Na redovnoj kontroli četrdeset dana nakon operacije urađena je analiza faktora koagulacije: INR 1.07; Fibrinogen 3.42; D-dimer 401; Antitrombin III 94.3\%. Funkcija trombocita urednog nalaza. Subjektivno bolesnica se oseća dobro, pedalne pulzacije palpabilne, nema ishemije ekstremiteta.

Tabela 1. Prikaz laboratorijskih parametara tokom hospitalizacije

\begin{tabular}{|l|c|c|c|c|c|c|}
\hline Laboratorijske analize & 0/postOP dan & 1. postOP dan & 1. postOP dan & 2. postOP dan & 3.postOP dan & 6. postOP dan \\
\hline Le & 17,6 & 15,5 & 19,7 & 19,4 & 18,1 & 15,0 \\
\hline Er & 3,34 & 2,24 & 3,32 & 2,89 & 2,76 & 2,76 \\
\hline Hgb & 98 & 68 & 98 & 88 & 83 & 81 \\
\hline Plt & 77 & 56 & 60 & 71 & 79 & 221 \\
\hline MCV & 84 & 85 & 81 & 81 & 83 & 84 \\
\hline SGOT & $/$ & $/$ & 16 & 165 & $/$ \\
\hline SGPT & $/$ & $/$ & 56 & 54 & $/$ & $/$ \\
\hline
\end{tabular}

Le-leukociti; Er-eritrociti; Hgb-hemoglobin; Plt-trombociti; $M C V$-srednja vrednost zapremine eritrocita;

SGOT- aspartat transferasa; SGPT- alanin transaminaza

Tabela 2. Prikaz globalnih testova hemostaze tokom hospitalizacije

\begin{tabular}{|l|l|l|l|l|}
\hline Analize & 0. postOP dan & 1. postOP dan & 2.postOP dan & 3.postOP dan \\
\hline INR & 1,51 & 1,14 & 1,18 & 0,99 \\
\hline AT & 43,7 & 76,3 & 68,7 & 81,1 \\
\hline Fib & 1,73 & 4,47 & 9,68 & 7,80 \\
\hline D-dimer & 4280 & 992 & 674 & 858 \\
\hline
\end{tabular}

INR-international normalized ratio; AT-antitrombin; Fib-fibrinogen; D-dimer
Tabela 3. Prikaz ROTEM testa tokom hospitalizacije

\begin{tabular}{|l|l|l|l|l|}
\hline ROTEM & $\mathbf{1 0 / 9}$ & $\mathbf{1 1 / 9}$ & $\mathbf{1 2 / 9}$ & $\mathbf{1 3 / 9}$ \\
\hline EXTEM CT & $98 \mathrm{~s}$ & $63 \mathrm{~s}$ & $79 \mathrm{~s}$ & $65 \mathrm{~s}$ \\
\hline EXTEM CFT & $199 \mathrm{~s}$ & $163 \mathrm{~s}$ & $103 \mathrm{~s}$ & $64 \mathrm{~s}$ \\
\hline EXTEMugao alfa & 55 & 67 & 74 & 77 \\
\hline INTEM CT & $360 \mathrm{~s}$ & $167 \mathrm{~s}$ & $181 \mathrm{~s}$ & $154 \mathrm{~s}$ \\
\hline INTEM CFT & $195 \mathrm{~s}$ & $147 \mathrm{~s}$ & $97 \mathrm{~s}$ & $70 \mathrm{~s}$ \\
\hline INTEM ugao alfa & 57 & 67 & 76 & 78 \\
\hline FIBTEM A10 & $3 \mathrm{~mm}$ & $13 \mathrm{~mm}$ & $25 \mathrm{~mm}$ & $10 \mathrm{~mm}$ \\
\hline FIBTEM ML & 0 & 11 & 0 & 0 \\
\hline
\end{tabular}

Extem-skrining test za koagulacioni deficit u spoljašnjem putu; Intem-skrining test za koagulacioni deficit u unutrašnjem putu; Fibtem-skrinig test za fibrinsku komponentu ugruška; Ct-detektuje poremećaj stvaranja ugruška; Mcf-detektuje stabilnost i kvalitet ugruška. 


\section{Diskusija}

Diseminovana intravskularna koagulacija (DIK) predstavlja patološko stanje aktivacije koagulacionog sistema. [1-3] Oba oblika ovog patološkog procesa, tromboza i krvarenje, dovode do teškog oštećenja funkcije više organa. [3]

Hemostazni poremećaji u DIK-u javljaju se u 4 povezana koraka. Tokom hiruške procedure dolazi do stvaranja trombina usled pojave tkivnog faktora u cirkulaciji, a usled deplecije antitrombina proteina $C$ dolazi do disfunkcije fiziološkog antikoagulantnog mehanizma. Usporeno je otklanjanje fibrinskih naslaga usled depresije fibrinolitičkog sistema te dolazi do aktivacija inflamacije. [4]

Plazmatski nivoi antitrombina (AT), najvažnijeg prirodnog inhibitora trombina, obično su veoma sniženi u bolesnika sa DIK-om, a razlozi za to su: AT se u kontinuitetu troši u aktivisanoj koagulaciji, gubi se i kapilarnim curenjem, a elastaza poreklom iz aktiviranih neutrofila razlaže antitrombin. Produkcija AT-a je takođe poremećena zbog hipofunkcije jetre usled hipoperfuzije i mikrovaskularne tromboze. [5] Procenjuje se da je DIK prisutan u $1 \%$ hospitalizovanih bolesnika, nezavisno od pola, godina i rase. [6] DIK se može javiti u akutnoj i hroničnoj formi. Bolesti krvnih sudova, kao što su velike aneurizme aorte, mogu lokalno prouzrokovati aktivaciju koagulacije. Tako aktivirani faktori koagulacije mogu preplaviti sistemsku cirkulaciju i vrlo kratkom vremenskom roku prouzrokovati pojavu akutnog DIK-a. Specifične trombotske komplikacije koje se viđaju u DIK-u su akralna cijanoza, hemoragijska infarkcija kože i ishemija ekstremiteta. Intravskularna depozicija fibrina, kao rezultat sistemske aktivacije koagulacije, vodi gubitku funkcije više organa, generalizovanom popuštanju i smrti. [7]

TF (tkivni faktor) se u cikulaciju oslobađa iz oštećenog endotela tkiva, ili inflamatornih ćelija koje nose prokoagulante molekule. Trombin koji je nastao aktivacijom kompleksa TF i faktora VIla ubrzava pojavu koa- gulacije krvi i sistemsku inflamaciju putem aktivacije trombocita, zatim faktora VIII, V, XI. Na inflamaciju utiče putem proteaza aktiviranih receptora, a takodje aktivira faktor XIII i TAFI zbog čega se formiraju trombotične mase otporne na fibrinolizu. [8]

Intravaskularna depozicija fibrina, koja je razultat sistemske aktivacije koagulacije, doprinosi poremećaju rada organa i smrti. Prognoza diseminovane intravskularne koagulacije zavisi od ozbiljnosti potrošne koagulopatije kao i oboljenja odnosno traume koja ga je izazvala.

Imajući u vidu prikaz našeg slučaja, rano prepoznavanje i postavljanje sumnje na poremećaj koagulacije i pojavu DIK-a rezultiralo je u ranoj detekciji ovog patološkog procesa te pravovremenom ordiniranju odgovarajuće terapije. Ova činjenica je doprinela brzom oporavku hemostaznog i imunološkog sistema i prevenciji budućih, potencijalno smtronosnih, hemoragičnih i trombogenih komplikacija.

\section{Zaključak}

Rano prepoznavanje poremećaja koagulacije, tokom operativnog zahvata od strane ordinirajućeg vaskularnog hirurga, u saradanji sa nadle- žnom transfuziološkom službom, je od velikog značaja u pravovremenoj detekciji i lečenju DIK-a te sprečavanju teških i potencijalno letalnih he- moragijski i trombogenih komplikacija kod ovih pacijenata.

\footnotetext{
Literatura

1. Balint B.Dijagnoza hemoragijskih sindroma i trombofilije. U.Transfuziologija Beograd. Zavod za udžbenike i nastavna sredstva 2004;295-355.

2. Levi M, Ten Cate H. Disseminated intravascular coagulation. N Engl J Med. 1999; 341(8):586-92.

3. Labar B,Hauptmann E i suradnici. Bolesti koagulacije. U. Hematologija Zagreb. Školska knjiga. 2007;309-321.
}

4. Franchini M, Lippi G, Manzato F. Recent acquisitins in the pathophysiology, diagnosis and treatement of disseminated intravascular coagulation. Thromb J. 2006;4:4.

5. Carey MJ, Rodgers GM. Disseminated intravascular coagulation: clinical and laboratory aspects. Am J Hematol. 1998,59(1):65-73.

6. Matsuda T. Clinical aspects of DIC. Pol J Pharmacol. 1996;48(1):41-9.
7. Levi M. Disseminated intravascular coagulation: What, new?. Crit Care Clin. 2005;21 (3):449-67.

8. Sower LE, Froelidh CJ, Carney DH, Fenton JW 2nd, Klimpel GR. Thrombin induces IL-6 production in fibroblasts and epithelial cells. Evidence for the involvement of the seven-transmembrane domain (STD) receptor for alpha-thrombin. J Immunol. 1995;155(2):895-901. 